\title{
Application of an advanced beam theory to ship hydroelastic analysis
}

\author{
I. Senjanović, S. Tomašević, N. Vladimir, M. Tomić \\ University of Zagreb, Faculty of Mechanical Engineering and Naval Architecture, Ivana Lučića 5, 10000 \\ Zagreb, CROATIA \\ S. Malenica \\ Bureau Veritas, 67/71 Boulevard du Châteu, 92200 Neuilly-sur-Seine, FRANCE
}

\begin{abstract}
Modern sea transport requires building of Very Large Container Ships (VLCS), which are relative flexible structures. Bearing in mind this fact, and taking into account the speed of VLCS, it is obvious that their natural frequencies could fall into the range of the encounter frequencies in an ordinary sea spectrum. Present Classification Rules for ship design and construction don't cover such conditions completely. This encourages scientists and engineers to develop more powerful and reliable tools for the analysis of ship behavior in seas and to improve the Rules. Hydroelastic analysis of VLCS seems to be appropriate solution for this challenging problem. Methodology of hydroelastic investigation is based on mathematical model which includes structural, hydrostatic and hydrodynamic submodels which are assembled into hydroelastic one. The hydroelastic problem can be solved at different levels of complexity and accuracy. It is obvious that the best way is to consider 3D FEM structural model and 3D hydrodynamic model, but this approach would be too expensive, especially in preliminary design stage. At this level it would be more appropriate to couple 1D FEM model of ship hull with 3D hydrodynamic model. In this paper, the emphasis is given on the advanced beam model which includes shear influence on torsion as an extension of shear influence on bending, and contribution of transverse bulkheads to hull stiffness. Beside structural model, hydrostatic and hydrodynamic submodels, as constitutive parts of hydroelastic model are briefly described. Verification of proposed numerical procedure is done by correlation analysis of the simulation results and the measured ones for flexible barge, for which the test results are available in the literature. Numerical example, which includes complete hydroelastic analysis of 7800 TEU container ship, is also given. In this case, validation of 1D FEM model is checked by correlation analysis with the vibration response of the fine 3D FEM model. The obtained results confirm that advanced thin-walled girder theory is a reasonable choice for determining wave load effects on VLCS, in preliminary design stage.
\end{abstract}

\section{INTRODUCTION}

Rapid increase in ship transport induces building of Very Large Container Ships (VLCS), which are relative slender, fast and quite flexible ships. Because of these features, structural natural frequencies of VLCS could fall into the range of encounter frequencies in an ordinary sea spectrum. It is very important to have reliable and powerful design tool to avoid those resonant stages during the navigation.

The classical theories for determination of ship motions and wave loads, as for example (Salvesen et al. 1970), are based on the assumption that the ship hull is a rigid body. Usually, the wave load obtained according to these theories is imposed to the elastic 3D FEM model of ship structure in order to analyze global strength, as well as local strength with stress concentrations related to fatigue analysis. Although the above approach is good enough for ships with closed cross-section and ordinary hatch openings such as tankers, bulk carriers or general cargo ships, it is not reliable as it should be for ultra large container ships due to mutual influence of the wave load and structure response (Senjanović et al. 2009a). Therefore, a more reliable solution requires analysis of wave load and ship vibration as a coupled hydroelastic problem (Bishop \& Price, 1979). This is very important for impulsive loads such as ship slamming which causes whipping.

Numerical procedure for ship hydroelastic analysis requires definition of structural model, ship and cargo mass distributions, and geometrical model of ship surface (Senjanović et al. 2007, 2008a, 2009b).

In this paper, the emphasis is given on advanced numerical procedure based on the beam and thinwalled girder theories for calculation of dry natural vibrations of container ships, as an important step in their hydroelastic analysis (Senjanović et al. 2009c). This theory includes shear influence on torsion as an extension of shear influence on bending, as well as contribution of transverse bulkheads to hull stiff- 
ness. Beside advanced beam theory, methodology of ship hydroelastic analysis is briefly described and illustrated. Also, short description of hydrostatic and hydrodynamic submodels, and hydroelastic model is given. Applied numerical procedure as well as developed computer codes is verified. Finally, the results of hydroelastic analysis of 7800 TEU container ship are given and properly interpreted.

\section{METHODOLOGY OF SHIP HYDROELASTIC ANALYSIS}

As mentioned before, structural model, ship and cargo mass distributions and geometrical model of ship surface have to be defined to make hydroelastic analysis of the ship. At the beginning of the analysis, dry natural vibrations have to be calculated, and after that modal hydrostatic stiffness, modal added mass, damping and modal wave load are determined. Finally, wet natural vibrations as well as the transfer functions (RAO) for determining ship structural response to wave excitation are obtained (Senjanović et al. 2008a, 2009b).

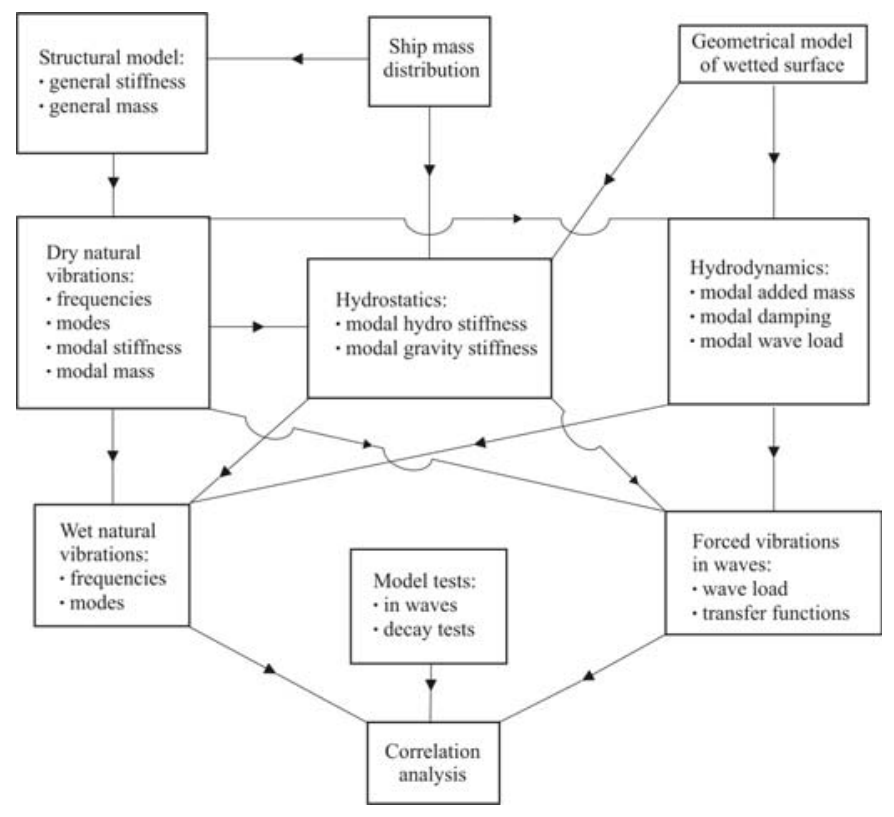

Figure 1. Methodology of the hydroelastic analysis.

\section{STRUCTURAL MODEL BASED ON ADVANCED BEAM THEORY}

\subsection{General remarks}

A ship hull, as an elastic non-prismatic thin-walled girder, performs longitudinal, vertical, horizontal and torsional vibrations. Since the cross-sectional centre of gravity and centroid, as well as the shear centre positions are not identical, coupled longitudinal and vertical, and horizontal and torsional vibrations occur, respectively. The distance between the centre of gravity and centroid for longitudinal and vertical vibrations, as well as distance between the former and shear centre for horizontal and torsional vibrations are negligible for conventional ships. Therefore, in the above cases ship hull vibrations can be analyzed separately. However, the shear centre in ships with large hatch openings is located outside the cross-section, i.e. below the keel, and therefore the coupling of horizontal and torsional vibrations is extremely high. The above problem is rather complicated due to geometrical discontinuity of the hull cross-section. The accuracy of the solution depends on the reliability of stiffness parameters determination, i.e. of bending, shear, torsional and warping moduli. The finite element method is a powerful tool to solve the above problem in a successful way. One of the first solutions for coupled horizontal and torsional hull vibrations, dealing with the finite element technique, is given in (Kawai, 1973, Senjanović \& Grubišić, 1991). Generalised and improved solutions are presented in (Pedersen, 1985, Wu \& Ho, 1987). In all these references, the determination of hull stiffness is based on the classical thin-walled girder theory, which does not give a satisfactory value for the warping modulus of the open cross-section (Haslum \& Tonnessen, 1972, Vlasov, 1961). Apart from that, the fixed values of stiffness moduli are determined, so that the application of the beam theory for hull vibration analysis is limited to a few lowest natural modes only. Otherwise, if the mode dependent stiffness parameters are used the application of the beam theory can be extended up to the tenth natural mode (Senjanović \& Fan, 1989, 1992, 1997).

\subsection{Outline of an advanced beam theory}

Referring to the flexural beam theory (Senjanović \& Grubišić, 1991), the total beam deflection, $w$, consists of the bending deflection, $w_{b}$, and the shear deflection, $w_{s}$, i.e., Figure 2

$w=w_{b}+w_{s}$.

The shear deflection is a function of $w_{b}$

$$
w_{s}=-\frac{E I_{b}}{G A_{s}} \frac{\partial^{2} w_{b}}{\partial x^{2}},
$$

where $E$ and $G$ are the Young's and shear modulus, respectively, while $I_{b}$, and $A_{s}$ are the moment of inertia of cross-section and shear area, respectively. The angle of cross-section rotation is caused by the bending deflection

$\varphi=\frac{\partial w_{b}}{\partial x}$.

The cross-sectional forces are the bending moment and the shear force 
$M=-E I_{b} \frac{\partial^{2} w_{b}}{\partial x^{2}}$,

$Q=G A_{s} \frac{\partial w_{s}}{\partial x}=-E I_{b} \frac{\partial^{3} w_{b}}{\partial x^{3}}$.

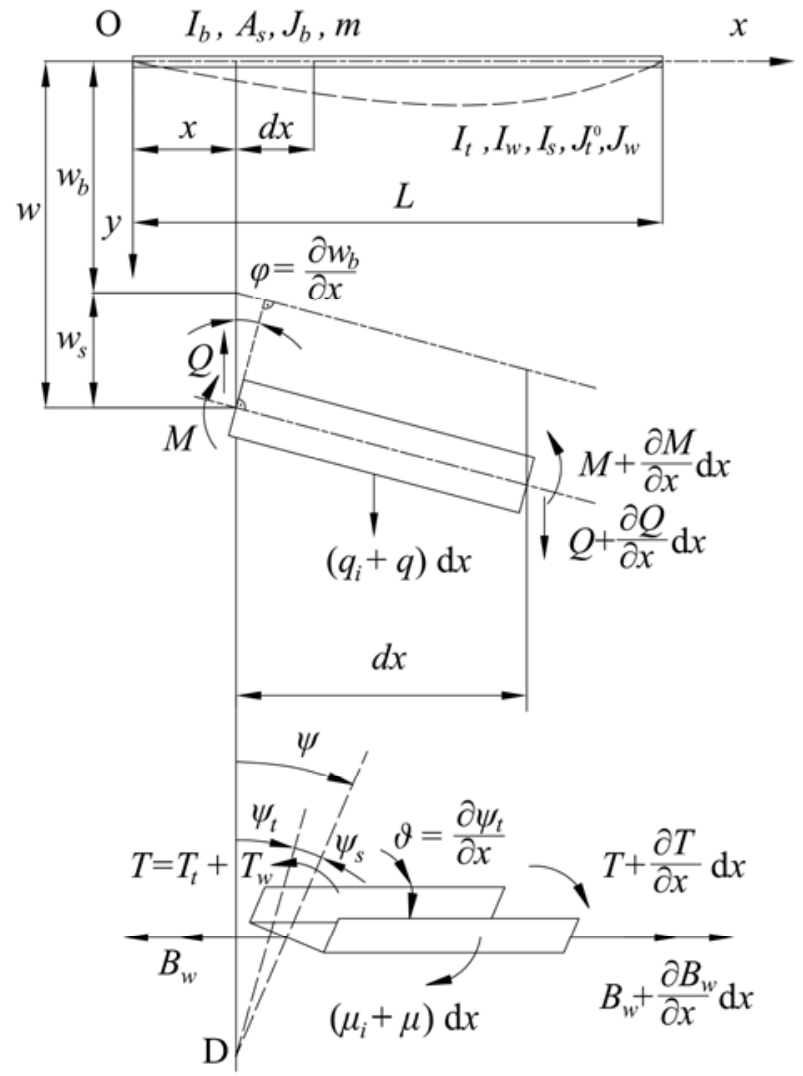

Figure 2. Beam bending and torsion.

Concerning torsion, the total twist angle, $\psi$, consists of the pure twist angle, $\psi_{t}$, and the shear contribution, $\psi_{s}$, i.e., Figure 2

$\psi=\psi_{t}+\psi_{s}$.

Referring to the analogy of torsion and bending (Pavazza, 2005), the shear angle depends on the twist angle, similarly to Eq. (2)

$\psi_{s}=-\frac{E I_{w}}{G I_{s}} \frac{\partial^{2} \psi_{t}}{\partial x^{2}}$,

where $I_{w}$ is the warping modulus and $I_{s}$ is the shear inertia modulus. The second beam displacement, which causes warping of cross-section (similarly to the cross-section rotation due to bending) is a variation of the pure twist angle

$\vartheta=\frac{\partial \psi_{t}}{\partial x}$.

The sectional forces include the total torque, $T$, which consists of pure torsional torque, $T_{t}$, and the warping torque $T_{w}$ i.e.

$T=T_{t}+T_{w}$, where

$$
T_{t}=G I_{t} \frac{\partial \psi_{t}}{\partial x}
$$

$T_{w}=G I_{s} \frac{\partial \psi_{s}}{\partial x}=-E I_{w} \frac{\partial^{3} \psi_{t}}{\partial x^{3}}$

and the bimoment given by

$$
B_{w}=E I_{w} \frac{\partial^{2} \psi_{t}}{\partial x^{2}} .
$$

1D FEM procedure for vertical ship hull vibrations is well known in literature. Coupled horizontal and torsional vibrations are a more complex problem. Due to analogy between bending and torsion the same shape functions, represented by Hermitian polynomials, are used. The matrix finite element equation for coupled vibration yields (Senjanović, 1998)

$\mathbf{f}^{\mathbf{e}}=\mathbf{k}^{\mathrm{e}} \boldsymbol{\delta}^{\mathbf{e}}+\mathbf{m}^{\mathrm{e}} \ddot{\boldsymbol{\delta}}^{\mathrm{e}}$,

where $\mathbf{f}^{\mathbf{e}}$ is nodal forces vector, $\delta^{\mathbf{e}}$ is nodal displacements vector, $\mathbf{k}^{\mathbf{e}}$ is stiffness matrix, and $\mathbf{m}^{\mathbf{e}}$ is mass matrix. These quantities consist of flexural and torsional parts

$$
\begin{aligned}
& \mathbf{f}^{\mathbf{e}}=\left\{\begin{array}{l}
\mathbf{P} \\
\mathbf{R}
\end{array}\right\}, \quad \boldsymbol{\delta}^{\mathbf{e}}=\left\{\begin{array}{l}
\mathbf{U} \\
\mathbf{V}
\end{array}\right\} \\
& \mathbf{k}^{\mathbf{e}}=\left[\begin{array}{cc}
\mathbf{k}_{\mathrm{bs}} & 0 \\
0 & \mathbf{k}_{\mathrm{wt}}
\end{array}\right], \quad \mathbf{m}^{\mathbf{e}}=\left[\begin{array}{ll}
\mathbf{m}_{\mathrm{sb}} & \mathbf{m}_{\mathrm{st}} \\
\mathbf{m}_{\mathrm{ts}} & \mathbf{m}_{\mathrm{tw}}
\end{array}\right] .
\end{aligned}
$$

Vectors of nodal forces and displacements are

$$
\begin{aligned}
& \mathbf{P}=\left\{\begin{array}{c}
-Q(0) \\
M(0) \\
Q(l) \\
-M(l)
\end{array}\right\}, \quad \mathbf{R}=\left\{\begin{array}{c}
-T(0) \\
-B_{w}(0) \\
T(l) \\
B_{w}(l)
\end{array}\right\} \\
& \mathbf{U}=\left\{\begin{array}{c}
w(0) \\
\varphi(0) \\
w(l) \\
\varphi(l)
\end{array}\right\}, \quad \mathbf{V}=\left\{\begin{array}{c}
\psi(0) \\
\vartheta(0) \\
\vartheta(l) \\
\vartheta(l)
\end{array}\right\} .
\end{aligned}
$$

In the above formulae symbols $Q, M, T$ and $B_{w}$ denote shear force, bending moment, torque and warping bimoment, respectively. Also, $w, \varphi, \psi$ and $\vartheta$ are deflection, rotation of cross-section, twist angle and its variation, respectively. The submatrices, which are specified in (Senjanović et al. 2009c), have the following meaning:

$\begin{array}{ll}\mathbf{k}_{\mathrm{bs}} & - \text { bending - shear stiffness matrix } \\ \mathbf{k}_{\mathrm{wt}} & \text { - warping - torsion stiffness matrix } \\ \mathbf{m}_{\mathrm{sb}} & \text { - shear - bending mass matrix } \\ \mathbf{m}_{\mathrm{tw}} & \text { - torsion - warping mass matrix } \\ \mathbf{m}_{\mathrm{st}}=\mathbf{m}_{\mathrm{ts}}{ }^{\mathrm{T}} \text { - } \text { - shear - torsion mass matrix. }\end{array}$


It is evident that coupling between horizontal and torsional vibrations is realized through the mass matrix due to eccentricity of the centre of gravity and shear centre.

Before assembling of finite elements it is necessary to transform Eq. (13) in such a way that all the nodal forces as well as nodal displacement, Eqs. (16) and (17), are related to the first and then to the second node. Furthermore, Eq. (13) has to be transformed from local to global coordinate system. The origin of the former is located at the shear centre, and of the latter at the base line.

\subsection{Contribution of transverse bulkheads to hull stiffness}

This problem for container ships is extensively analyzed in (Senjanović et al. 2008b), where torsional modulus of ship cross-section is increased proportionally to the bulkhead strain energy. The bulkhead is considered as an orthotropic plate with very strong stool (Szilard, 2004). The bulkhead strain energy is determined for the given warping of cross-section as a boundary condition. The warping causes bulkhead screwing and bending. Here, only the review of the final results is presented. The bulkhead deflection (axial displacement) is given by the following formula, Figure 3:

$$
u(y, z)=-y\left\{(z-d)+\left[1-\left(\frac{y}{b}\right)^{2}\right] \frac{z^{2}}{H}\left(2-\frac{z}{H}\right)\right\} \psi^{\prime},
$$

where $H$ is the ship height, $b$ is one half of bulkhead breadth, $d$ is the distance of warping centre from double bottom neutral line, $y$ and $z$ are transverse and vertical coordinates, respectively, and $\psi^{\prime}$ is the variation of twist angle.

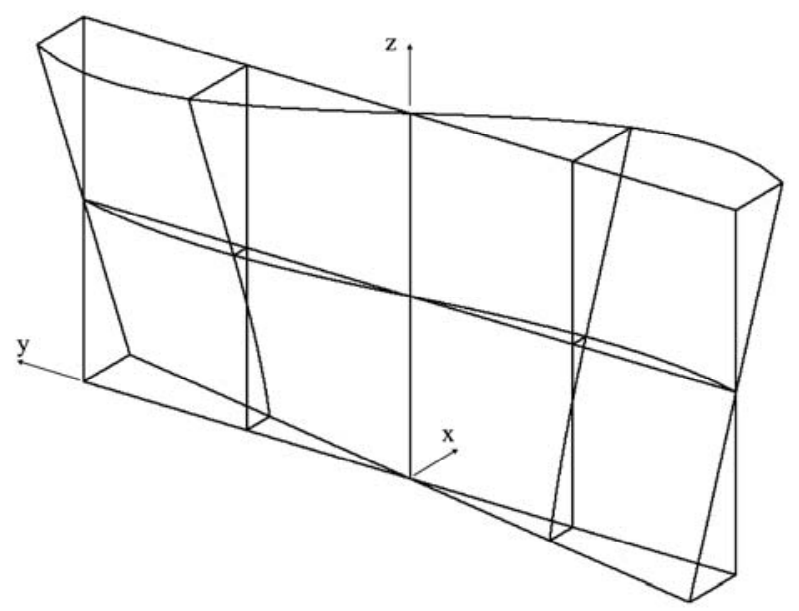

Figure 3. Shape of bulkhead deformation.

The bulkhead grillage strain energy includes vertical and horizontal bending with contraction, and torsion (Senjanović et al. 2008b).

$$
\begin{aligned}
& U_{g}=\frac{1}{1-v^{2}}\left[\frac{116 H^{3}}{35 b} i_{y}+\frac{32 b^{3}}{105 H} i_{z}+\frac{8 H b}{75} v\left(i_{y}+i_{z}\right)\right. \\
& \left.+\frac{143 H b}{75}(1-v) i_{t}\right] E \psi^{\prime 2}
\end{aligned}
$$

where $i_{y}, i_{z}$ and $i_{t}$ are the average moments of inertia of cross-section and torsional modulus per unit breadth, respectively. The stool strain energy is comprised of the bending, shear and torsional contributions

$$
U_{s}=\left[\frac{12 h^{2} I_{s b}}{b}+72(1+v) \frac{h^{2}}{b^{3}} \frac{I_{s b}^{2}}{A_{s}}+\frac{9 b I_{s t}}{10(1+v)}\right] E \psi^{\prime 2}
$$

where $I_{s b}, A_{s}$ and $I_{s t}$ are the moment of inertia of cross-section, shear area and torsional modulus, respectively. Quantity $h$ is the stool distance from the inner bottom, Figure 4.

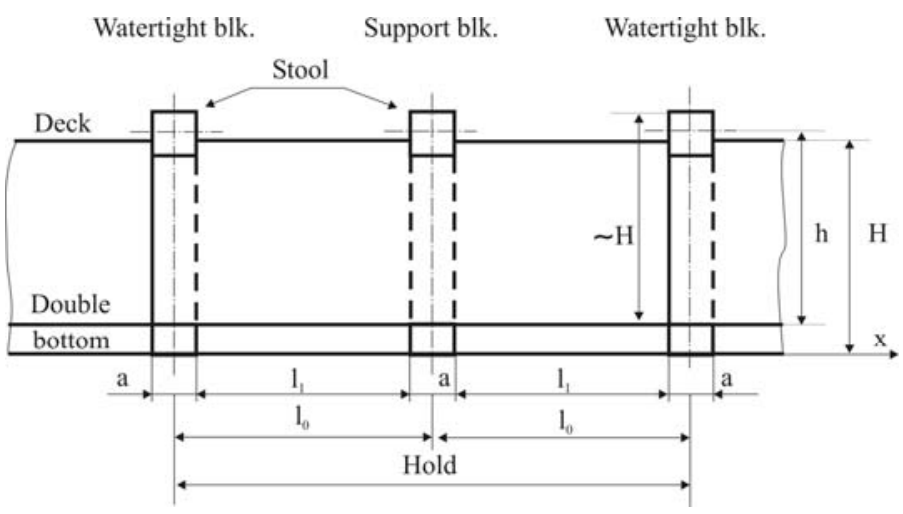

Figure 4. Longitudinal section of container ship hold.

The equivalent torsional modulus yields, Figure 4

$I_{t}^{*}=\left[1+\frac{a}{l_{1}}+\frac{4(1+v) C}{I_{t} l_{0}}\right] I_{t}$,

where $a$ is the web height of bulkhead girders (frame spacing), $l_{0}$ is the bulkhead spacing, $l_{1}=l_{0}-a$ is the net length, and $C$ is the energy coefficient

$C=\frac{U_{g}+U_{s}}{E \psi^{\prime 2}}$.

The second term in (21) is the main contribution of the bulkhead as the closed cross-section segment of ship hull, and the third one comprises the bulkhead strain energy.

\subsection{Natural vibration analysis}

If the FEM approach is used (1D or 3D model), the governing equation of dry natural vibrations yields (Bathe, 1996)

$$
\left(\mathbf{K}-\Omega^{2} \mathbf{M}\right) \boldsymbol{\delta}=\mathbf{0},
$$


where $\mathbf{K}$ is stiffness matrix, $\mathbf{M}$ is mass matrix, $\Omega$ is dry natural frequency and $\boldsymbol{\delta}$ is dry natural mode. As solution of the eigenvalue problem (23) $\Omega_{i}$ and $\boldsymbol{\delta}_{i}$ are obtained for each the $i$-th dry mode, where $i=1,2 \ldots N, N$ is total number of degrees of freedom. Now natural modes matrix can be constituted

$$
\boldsymbol{\delta}=\left[\boldsymbol{\delta}_{1}, \boldsymbol{\delta}_{2} \ldots \boldsymbol{\delta}_{i} \ldots \boldsymbol{\delta}_{N}\right]
$$

and the modal stiffness and mass can be determined (Senjanović, 1998)

$$
\mathbf{k}=\boldsymbol{\delta}^{T} \mathbf{K} \boldsymbol{\delta}, \quad \mathbf{m}=\boldsymbol{\delta}^{T} \mathbf{M} \boldsymbol{\delta} .
$$

Since the dry natural vectors are mutually orthogonal, matrices $\mathbf{k}$ and $\mathbf{m}$ are diagonal. Terms $k_{i}$ and $\Omega_{i}^{2} m_{i}$ represent strain and kinetic energy of the $i$-th mode respectively.

Note that generally the first six natural frequencies $\Omega_{i}$ are zero with corresponding eigenvectors representing the rigid body modes. As a result, the first six diagonal elements of $\mathbf{k}$ are also zero, while the first three elements in $\mathbf{m}$ are equal to structure mass, the same in all directions $x, y, z$, and the next three elements represent the mass moment of inertia around the corresponding coordinate axes.

If $1 \mathrm{D}$ analysis is applied, the beam modes are spread to the ship wetted surface using the expressions for vertical vibrations (Senjanović et al. 2009a)

$\mathbf{h}_{i}=-\frac{\mathrm{d} w_{v i}}{\mathrm{~d} x}\left(z-z_{N}\right) \mathbf{i}+w_{v i} \mathbf{k}$,

and for coupled horizontal and torsional vibrations

$$
\begin{aligned}
\mathbf{h}_{i} & =\left(-\frac{\mathrm{d} w_{h i}}{\mathrm{~d} x} y+\frac{\mathrm{d} \psi_{i}}{\mathrm{~d} x} \bar{u}\right) \mathbf{i} \\
& +\left[w_{h i}+\psi_{i}\left(z-z_{S}\right)\right] \mathbf{j}-\psi_{i} y \mathbf{k},
\end{aligned}
$$

where $w$ is hull deflection, $\psi$ is twist angle, $y$ and $z$ are coordinates of the point on ship surface, and $z_{N}$ and $z_{S}$ are coordinates of centroid and shear centre respectively, and $\bar{u}=\bar{u}(x, y, z)$ is the cross-section warping intensity reduced to the wetted surface (Senjanović et al. 2009d).

\section{HYDRODYNAMIC MODEL}

The coupling procedure does not depend on the used hydrodynamic model, and is therefore described here for the zero speed case, as the simplest one. Harmonic hydroelastic problem is considered in frequency domain and therefore we operate with amplitudes of forces and displacements. In order to perform the coupling of structural and hydrodynamic models, it is necessary to express the external pressure forces in a convenient manner (Malenica et al. 2003). First, the total hydrodynamic force $F^{h}$ has to be split into two parts: the first part $F^{R}$ depending on the structural deformations, and the second one
$F^{D I}$ representing the pure excitation. Furthermore, the modal superposition method can be used. Vector of the wetted surface deformations $\mathbf{H}(x, y, z)$ can be presented as a series of dry natural modes $\mathbf{h}_{i}(x, y, z)$.

The potential theory assumptions are adopted for the hydrodynamic part of the problem. Within this theory, the total velocity potential $\varphi$, in the case of no forward speed, is defined with the Laplace differential equation and the given boundary values. Furthermore, the linear wave theory enables the following decomposition of the total potential (Senjanović et al. 2008a)

$$
\varphi=\varphi_{I}+\varphi_{D}-i \omega \sum_{j=1}^{N} \xi_{j} \varphi_{R j}, \quad \varphi_{I}=-i \frac{g A}{\omega} \mathrm{e}^{v(z+i x)},
$$

where $\varphi_{I}$ is incident wave potential, $\varphi_{D}$ is diffraction potential, $\varphi_{R j}$ is radiation potential and $A$ and $\omega$ represent wave amplitude and frequency respectively. Once the potentials are determined, the modal hydrodynamic forces are calculated by pressure work integration over the wetted surface, $S$. The total linearised pressure can be found from Bernoulli's equation

$p=i \omega \rho \varphi-\rho g z$.

First, the term associated with the velocity potential $\varphi$ is considered and subdivided into excitation and radiation parts

$F_{i}^{D I}=i \omega \rho \iint_{S}\left(\varphi_{I}+\varphi_{D}\right) \mathbf{h}_{i} \mathbf{n} \mathrm{d} S$,

$F_{i}^{R}=\rho \omega^{2} \sum_{j=1}^{N} \xi_{j} \iint_{S} \varphi_{R j} \mathbf{h} \mathbf{n} \mathrm{d} S$.

Thus, $F_{i}^{D I}$ represents the modal pressure excitation. Now one can decompose (31)into the modal inertia force and damping force associated with acceleration and velocity, respectively

$F_{i}^{a}=\operatorname{Re}\left(F_{i}^{R}\right)=\omega^{2} \sum_{j=1}^{N} \xi_{j} A_{i j}, A_{i j}=\rho \operatorname{Re} \iint_{S} \varphi_{R j} \mathbf{h}_{i} \mathbf{n} \mathrm{d} S$,

$F_{i}^{v}=\operatorname{Im}\left(F_{i}^{R}\right)=\omega \sum_{j=1}^{N} \xi_{j} B_{i j}, \quad B_{i j}=\rho \omega \operatorname{Im} \iint_{S} \varphi_{R j} \mathbf{h}_{i} \mathbf{n} \mathrm{d} S$

where $A_{i j}$ and $B_{i j}$ are elements of added mass and damping matrices, respectively.

Determination of added mass and damping for rigid body modes is a well-known procedure in ship hydrodynamics. Now the same procedure is extended to the calculation of these quantities for elastic modes. The hydrostatic part of the total pressure, $-\rho g z$ in (29), is considered within the hydrostatic model. 


\section{HYDROSTATIC MODEL}

Hydroelasticity is a known issue for many years, and there are few solutions for restoring stiffness (Price \& Wu, 1985, Newman, 1994, Huang \& Riggs, 2000, Malenica, 2003). In this study consistent formulation of restoring stiffness is used (Senjanović et al. 2009a, b), and its condensed form is given below.

The restoring stiffness consists of hydrostatic and gravity parts. Work of the hydrostatic pressure, which represents the generalized force, can be derived in the following form

$$
F^{h}=-\rho g \iint_{S}\left[H_{z}+Z(\nabla \mathbf{H})\right] \mathbf{H n d} S,
$$

where $\nabla$ is Hamilton differential operator, $\mathbf{H}$ is displacement vector, $\mathrm{d} S$ is differential of wetted surface, $Z$ is its depth and $\mathbf{n}$ is unit normal vector. According to definition, the stiffness is relation between incremental force and displacement, so it is determined from the variational equation

$$
\delta F^{h}=-\rho g \iint_{S}\left[H_{z}+Z(\nabla \mathbf{H})\right] \delta \mathbf{H n d} S .
$$

Furthermore, the modal superposition method is used, and the variation is transmitted to modes, i.e. modal forces and displacements

$$
\delta F^{h}=\sum_{j=1}^{N} \delta F_{j}^{h}, \quad \mathbf{H}=\sum_{j=1}^{N} \xi_{j} \mathbf{h}_{j}, \quad \delta \mathbf{H}=\sum_{j=1}^{N} \mathbf{h}_{j} \delta \xi_{j} .
$$

In that way, Eq. (35) is decomposed into the modal equations

$$
\delta F_{i}^{h}=-\sum_{j=1}^{N}\left[\left(C_{i j}^{p}+C_{i j}^{n h}\right) \xi_{j}\right] \delta \xi_{i},
$$

where

$$
C_{i j}^{p}=\rho g \iint_{S} \mathbf{h}_{i} h_{z}^{j} \mathbf{n} \mathrm{d} S, \quad C_{i j}^{n h}=\rho g \iint_{S} Z \mathbf{h}_{i}\left(\nabla \mathbf{h}_{j}\right) \mathbf{n} \mathrm{d} S,
$$

are stiffness coefficients due to pressure, and normal vector and mode contributions, respectively.

Similarly to the pressure part, the generalized gravity force reads

$$
F^{m}=-g \iiint_{V} \rho_{s}(\mathbf{H} \nabla) H_{z} \mathrm{~d} V,
$$

where $\rho_{s}$ and $V$ are structure density and volume, respectively. In order to obtain consistent variational equation, it is necessary to strictly follow the definition of stiffness and to vary displacement vector in (39) and not its derivatives

$$
\delta F^{m}=-g \iiint_{V} \rho_{s}(\delta \mathbf{H} \nabla) H_{z} \mathrm{~d} V .
$$

Application of the modal superposition method leads to the modal variational equation $\delta F_{i}^{m}=-\sum_{j=1}^{N} C_{i j}^{m} \xi_{j} \delta \xi_{i}$,

where

$$
C_{i j}^{m}=g \iiint_{V} \rho_{s}\left(\mathbf{h}_{i} \nabla\right) h_{z}^{j} \mathrm{~d} V,
$$

are the gravity stiffness coefficients. Finally, the complete restoring stiffness coefficients are obtained by summing up its constitutive parts

$C_{i j}=C_{i j}^{p}+C_{i j}^{n h}+C_{i j}^{m}$.

\section{HYDROELASTIC MODEL}

After the definition of the structural, hydrostatic and hydrodynamic models, the hydroelastic model can be constituted. The governing matrix differential equation for coupled ship motions and vibrations is deduced

$\left[\mathbf{k}+\mathbf{C}-i \omega(\mathbf{d}+\mathbf{B}(\omega))-\omega^{2}(\mathbf{m}+\mathbf{A}(\omega))\right] \xi=\mathbf{F}$,

where $\mathbf{k}, \mathbf{d}$, and $\mathbf{m}$ are structural stiffness, damping and mass matrices, respectively, $\mathbf{C}$ is restoring stiffness, $\mathbf{B}(\omega)$ is hydrodynamic damping, $\mathbf{A}(\omega)$ is added mass, $\boldsymbol{\xi}$ is modal amplitudes, $\mathbf{F}$ is wave excitation and $\omega$ is encounter frequency. All quantities, except $\omega$ and $\xi$, are related to the dry modes. The solution of (44) gives the modal amplitudes $\xi_{i}$ and displacement of any point of the structure obtained by retracking to (36).

\section{VERIFICATION OF PROPOSED NUMERICAL PROCEDURE}

The computer software DYANA for ship hydroelastic analysis, based on the presented theory, has been developed. Both theory and code are checked by correlation analysis of the simulation results and the measured ones for a flexible segmented barge consisting of 12 pontoons, for which test results are available (Malenica et al. 2003, Remy et al. 2006), Figure 5. Good agreement between measured and calculated transfer functions of horizontal bending moment and torque, as function of wave period, $T$, implies that developed procedure can be used for ship hydroelastic analysis, Figures 6, 7 (Malenica et al. 2003, 2007). Also, convergence of the applied modal superposition method in hydroelastic analysis is confirmed in the case of the same flexible barge with no forward speed (Tomašević, 2007). Figure 8 shows absolute amplitude values $\xi_{\mathrm{i}}$ of normalized modes. The first three modes are related to sway, roll and yaw, while the remaining modes are elastic. 


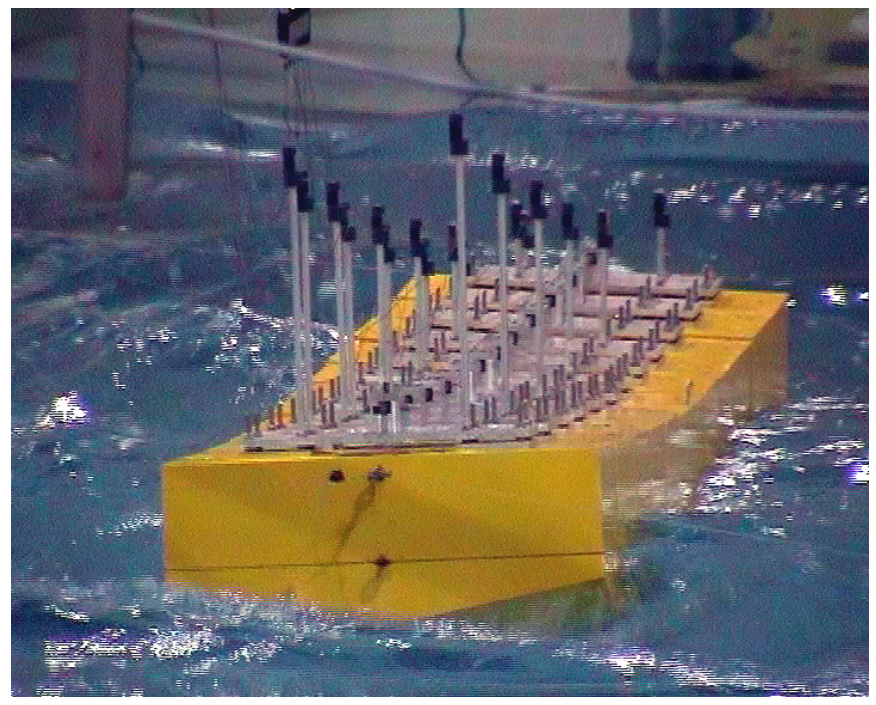

Figure 5. Barge test in waves.

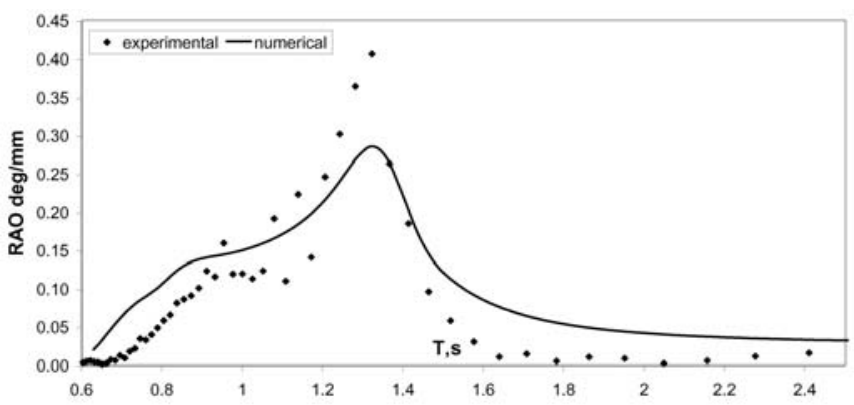

Figure 6. Transfer function of barge horizontal bending moment, $\chi=60^{\circ}$.

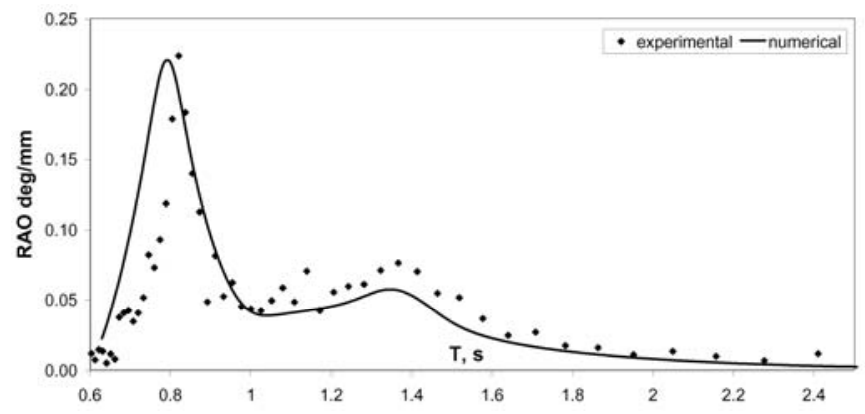

Figure 7. Transfer function of barge torque, $\chi=60^{\circ}$.

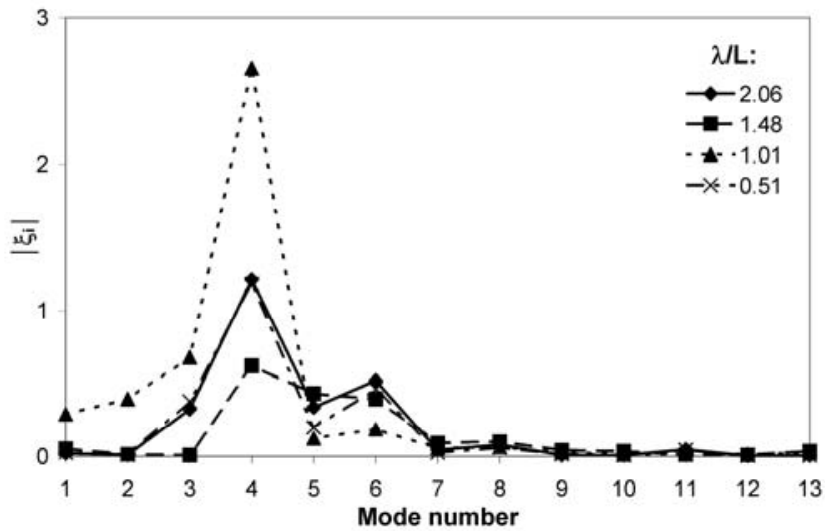

Figure 8. Modal amplitudes of coupled horizontal and torsional vibrations of flexible barge, $V=0 \mathrm{kn}, \chi=120^{\circ}$.

\section{NUMERICAL EXAMPLE}

For the illustration purposes, hydroelastic analysis of 7800 TEU VLCS is done, Figure 9.

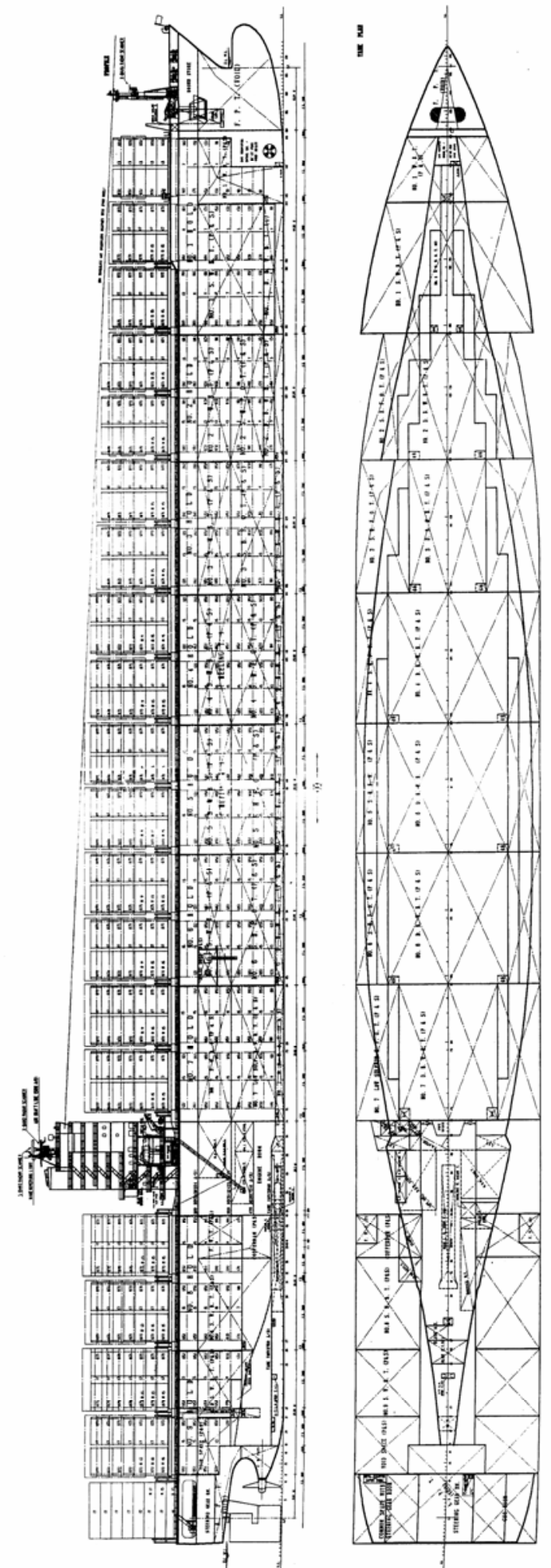

Figure 9. 7800 TEU Container Ship.

\subsection{Particulars of the analyzed ship}

The main vessel particulars are the following: Length overall $L_{o a}=334 \mathrm{~m}$

Length between perpendiculars $L_{p p}=319 \mathrm{~m}$ Breadth $B=42.8 \mathrm{~m}$ 
Depth

Draught

Displacement, full load

Displacement, ballast

Engine power

Ship speed

The midship section, which shows a double skin structure with the web frames and longitudinals, is presented in Figure 10. Rows and tiers of containers at the midship section are indicated in Figure 11. Vertical positions of neutral line, deformation (shear, torsional) centre, and centre of gravity are also marked in the figure. Large distance between gravity centre and deformation centre causes high coupling of horizontal and torsional vibrations.

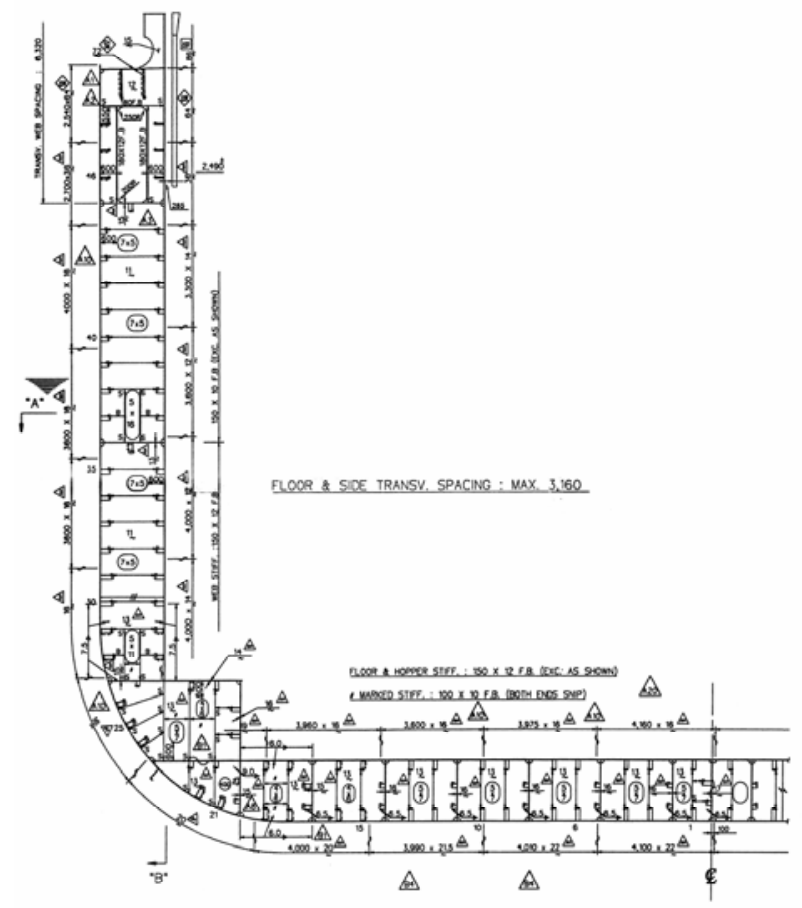

Figure 10. Midship section of the analyzed ship.

The ship hull stiffness properties are calculated by program STIFF, based on the theory of thin-walled girders (Senjanović \& Fan, 1992, 1993). The geometrical properties rapidly change values in the engine and superstructure area due to closed ship cross-section. This is especially pronounced in case of torsional modulus, which takes quite small values for open cross-section and rather high for the closed one (Tomašević, 2007).

Influence of the transverse bulkheads is taken into account by using the equivalent torsional modulus for the open cross-sections instead of the actual values, i.e. $I_{t}^{*}=2.4 I_{t}$. This value is applied for all shipcross sections as the first approximation. The stiffness parameters of the bulkhead girders are listed in
Tables 1 and 2, while the stool parameters are given in Table 3.

Table 1. Stiffness parameters of watertight bulkhead.

\begin{tabular}{cccccc}
\hline $\begin{array}{c}\text { Girde } \\
\mathrm{r}\end{array}$ & $\begin{array}{c}\text { Moment } \\
\text { of inertia }\end{array}$ & $\begin{array}{c}\text { Tors. } \\
\text { modulu } \\
\mathrm{s}\end{array}$ & $\begin{array}{c}\text { Spac- } \\
\text { ing }\end{array}$ & $\begin{array}{c}\text { Moment } \\
\text { of inertia }\end{array}$ & $\begin{array}{c}\text { Tors. } \\
\text { modulu } \\
\mathrm{s}\end{array}$ \\
\hline & $I\left(\mathrm{~m}^{4}\right)$ & $I_{t}\left(\mathrm{~m}^{4}\right)$ & $c(\mathrm{~m})$ & $i\left(\mathrm{~m}^{3}\right)$ & $i_{t}\left(\mathrm{~m}^{3}\right)$ \\
Horiz. & 0.02356 & 0.01555 & 2.6 & 0.00906 & 0.00493 \\
Vert. & 0.04196 & 0.03205 & 7.9 & 0.00531 & \\
\hline
\end{tabular}

Table 2. Stiffness parameters of support bulkhead.

\begin{tabular}{cccccc}
\hline $\begin{array}{c}\text { Girde } \\
\mathrm{r}\end{array}$ & $\begin{array}{c}\text { Moment } \\
\text { of inertia }\end{array}$ & $\begin{array}{c}\text { Tors. } \\
\text { modulu } \\
\mathrm{s}\end{array}$ & $\begin{array}{c}\text { Spac- } \\
\text { ing }\end{array}$ & $\begin{array}{c}\text { Moment } \\
\text { of inertia }\end{array}$ & $\begin{array}{c}\text { Tors. } \\
\text { modulu } \\
\mathrm{s}\end{array}$ \\
\hline & $I\left(\mathrm{~m}^{4}\right)$ & $I_{t}\left(\mathrm{~m}^{4}\right)$ & $c(\mathrm{~m})$ & $i\left(\mathrm{~m}^{3}\right)$ & $i_{t}\left(\mathrm{~m}^{3}\right)$ \\
Horiz. & 0.00972 & 0.00486 & 2.6 & 0.00374 & 0.001696 \\
Vert. & 0.01944 & 0.01215 & 7.9 & 0.00246 & \\
\hline
\end{tabular}

Table 3. Stool stiffness parameters.

\begin{tabular}{ccc}
\hline Shear area & Moment of inertia & Tors. modulus \\
\hline$A_{s}\left(\mathrm{~m}^{2}\right)$ & $I_{s}\left(\mathrm{~m}^{4}\right)$ & $I_{t s}\left(\mathrm{~m}^{4}\right)$ \\
0.45 & 0.07804 & 0.131 \\
\hline
\end{tabular}

The bulkhead strain energy, determined according to formulae presented in Chapter 3 is given in Table 4 .

Table 4. Bulkhead strain energy, $U /\left(E \psi^{\prime 2}\right)$.

\begin{tabular}{|c|c|c|c|c|}
\hline \multicolumn{2}{|c|}{ Watertight bulkhead } & \multicolumn{2}{|c|}{ Support bulkhead } & $\begin{array}{l}\text { Energy coeffi- } \\
\text { cient }\end{array}$ \\
\hline Grillage & Stool & Grillage & Stool & $C$, Eq. (C5) \\
\hline (1) & (2) & (3) & (4) & $\begin{array}{c}(5)=[(1)+(2)+ \\
(3)+(4)] / 2\end{array}$ \\
\hline 29.691 & 28.872 & 12.051 & 28.872 & 49.743 \\
\hline
\end{tabular}

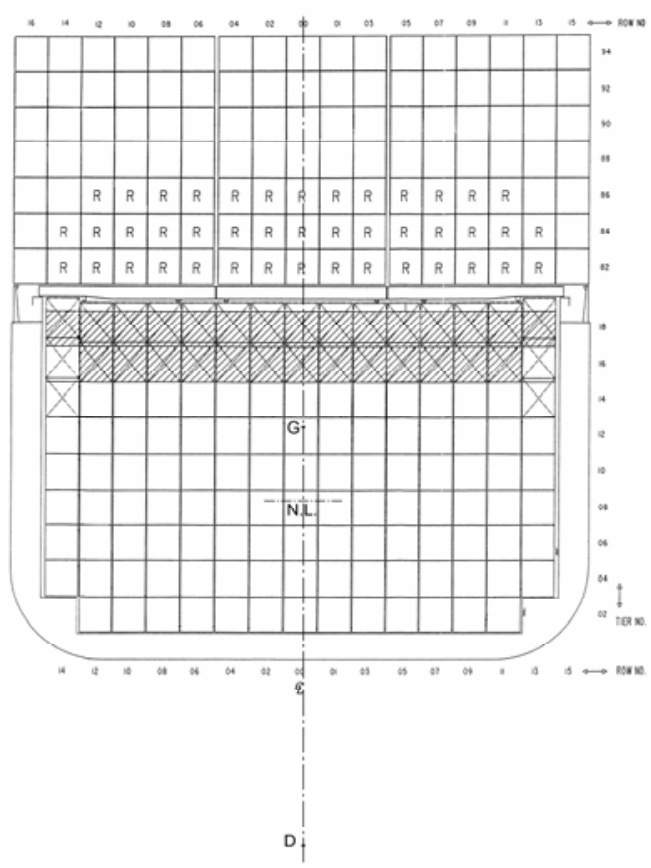

Figure 11. Container distribution at midship section. 


\subsection{Validation of $1 D$ FEM model}

The reliability of 1D FEM analysis is verified by 3D FEM analysis of the considered ship. For this purpose, the light weight loading condition of dry ship with displacement $\Delta=33692 \mathrm{t}$ is taken into account. The lateral and bird view of the first dominantly torsional mode of the wetted surface, determined by 1D model, is shown in Figure 12. The first 3D dry coupled natural modes of the complete ship structure is shown in Figure 13, where $Y$ and $Z$ are vertical and transversal axis, respectively. It is similar to that of 1D analysis for the wetted surface. Warping of the transverse bulkheads, which increases the hull torsional stiffness, is evident.
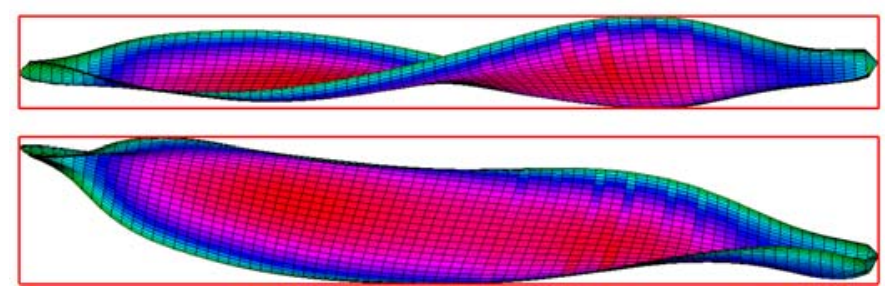

Figure 12. The first dominantly torsional mode, lateral and bird view, light weight, 1D model.

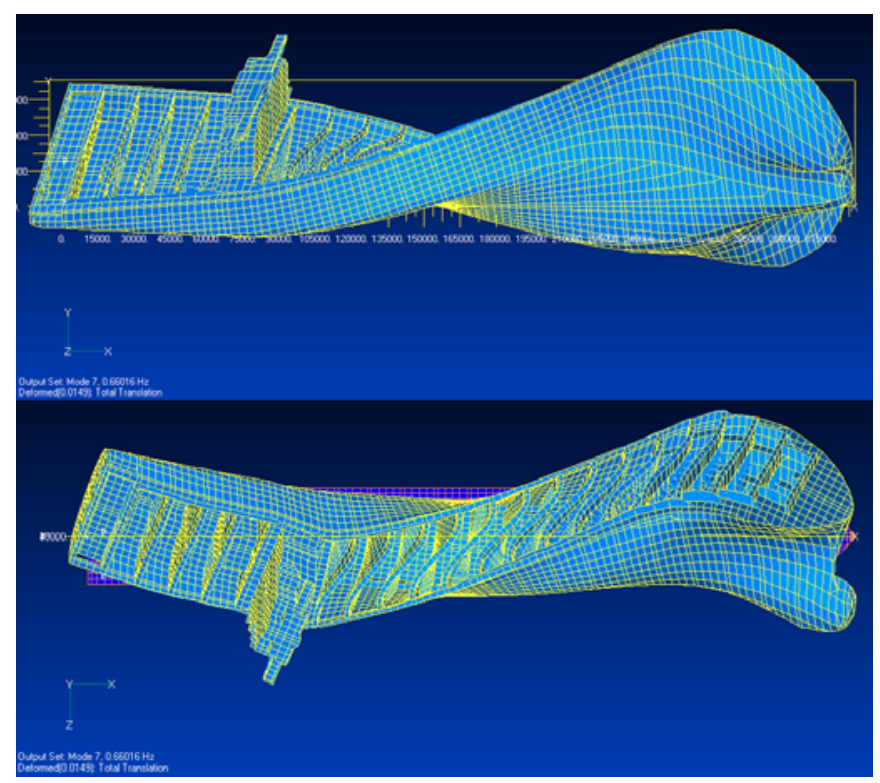

Figure 13. The first dominantly torsional mode, lateral and bird view, light weight, 3D model.

The first four corresponding natural frequencies obtained by $1 \mathrm{D}$ and 3D analyses are compared in Table 5.

$\underline{\text { Table 5. Dry natural frequencies, light weight, } \omega_{i}[\mathrm{rad} / \mathrm{s}]}$.

\begin{tabular}{cccccc}
\hline \multirow{2}{*}{$\begin{array}{c}\text { Mod } \\
\text { e no. }\end{array}$} & \multicolumn{3}{c}{ Vert. } & \multicolumn{3}{c}{ Horiz. + tors. } & \multirow{2}{*}{ Mode no. } \\
\cline { 2 - 5 } & 1D & $3 \mathrm{D}$ & 1D & 3D & \\
\hline 1 & 7.35 & 7.33 & 4.17 & 4.15 & $1(\mathrm{H} 0+\mathrm{T} 1)$ \\
2 & 15.00 & 14.95 & 7.34 & 7.40 & $2(\mathrm{H} 1+\mathrm{T} 2)$ \\
3 & 24.04 & 22.99 & 12.22 & 12.09 & $3(\mathrm{H} 2+\mathrm{T} 3)$ \\
4 & 35.08 & 34.21 & 15.02 & 16.22 & $4(\mathrm{H} 3+\mathrm{T} 4)$ \\
\hline
\end{tabular}

Quite good agreement is achieved. Values of natural frequencies for higher modes are more difficult to correlate, since strong coupling between global hull modes and local substructure modes of $3 \mathrm{D}$ analysis occurs.

\subsection{Results of the ship response calculation}

Transfer functions of torsional moment and horizontal bending moment at the midship section are shown in Figures 14 and 15, respectively. They are compared to the rigid body ones determined by program HYDROSTAR. Very good agreement is obtained in the lower frequency domain, where the ship behaves as a rigid body. Discrepancies are very large at the resonances of the elastic modes, as expected.

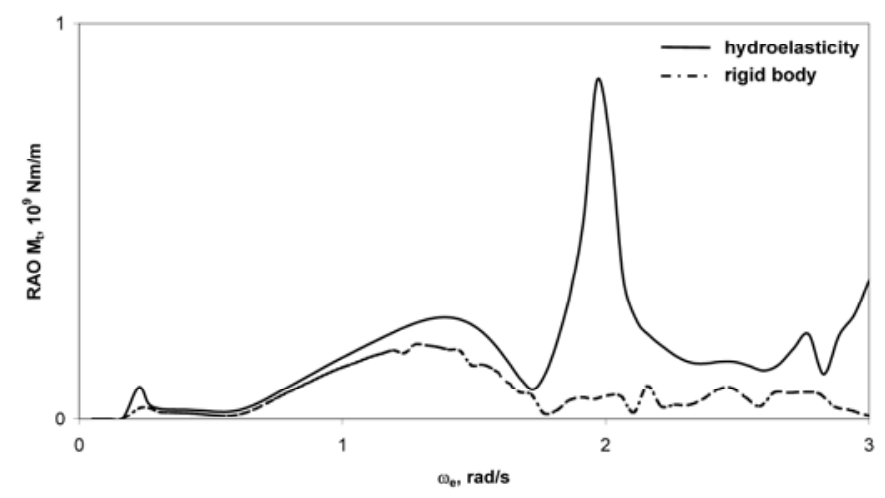

Figure 14. Transfer function of torsional moment, $\chi=120^{\circ}$, $U=25 \mathrm{kn}, x=155.75 \mathrm{~m}$ from AP.

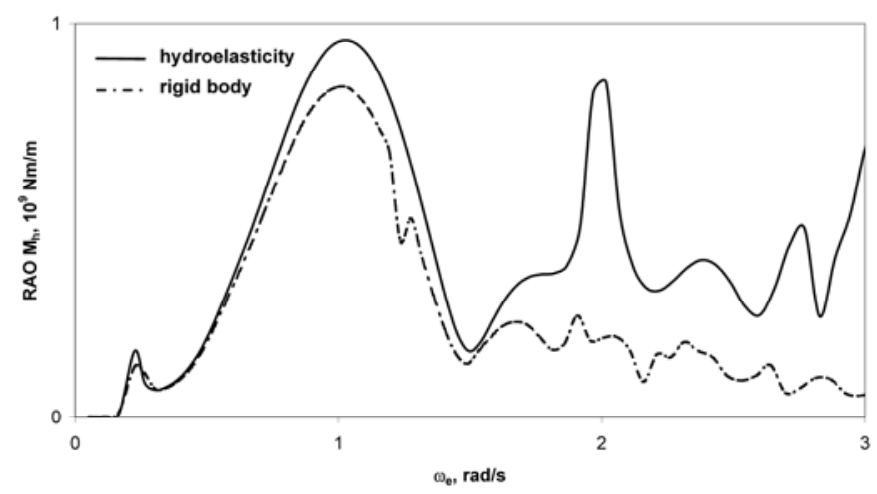

Figure 15. Transfer function of horizontal bending moment, $\chi=120^{\circ}, U=25 \mathrm{kn}, x=155.75 \mathrm{~m}$ from AP.

Necessary condition for convergence of sectional forces to zero value as the wave frequency approaches to zero can be used as a benchmark for validation of the restoring stiffness. Figure 16 shows the zoomed transfer function of torsional moment determined by the direct integration and three formulations of restoring stiffness in the hydroelastic approach: consistent one from this paper, symmetric matrix $\bar{C}_{i j}=\left(C_{i j}+C_{j i}\right) / 2$ obtained by the minimum energy method, and hybrid matrix in which $C_{i j}^{* p}=C_{i j}^{p}, \quad C_{i j}^{* n}=C_{i j}^{n}, \quad C_{i j}^{* h}=C_{j i}^{h}, \quad C_{i j}^{* m}=C_{j i}^{m}$, 
(Malenica, 2003). Only the consistent restoring stiffness satisfies the above condition as the rigid body solution does. In the case of symmetric and hybrid matrices the ship is not equilibrated. Moreover, the consistent restoring stiffness emphasizes the roll resonance at $0.23 \mathrm{rad} / \mathrm{s}$.

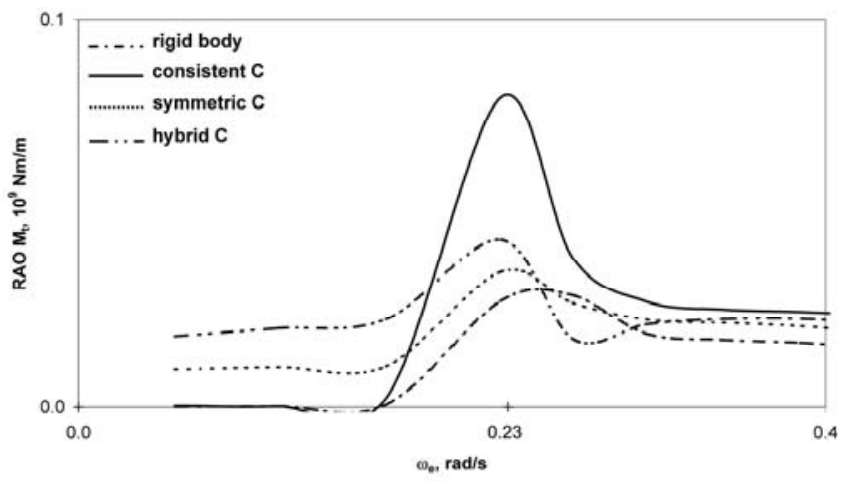

Figure 16. Zoomed transfer function of torsional moment, $\chi=120^{\circ}, U=25 \mathrm{kn}, x=155.75 \mathrm{~m}$ from AP.

Shear influence on torsion is investigated in the case of a pontoon with the cross-section equal to the midship section of the considered 7800 container ship. One end of the pontoon is fixed and another is loaded with the concentrated torque. Calculation is performed analytically by employing the advanced beam theory and numerically by 3D FEM model. Rotation angles of the free pontoon end are shown in Figure 17.

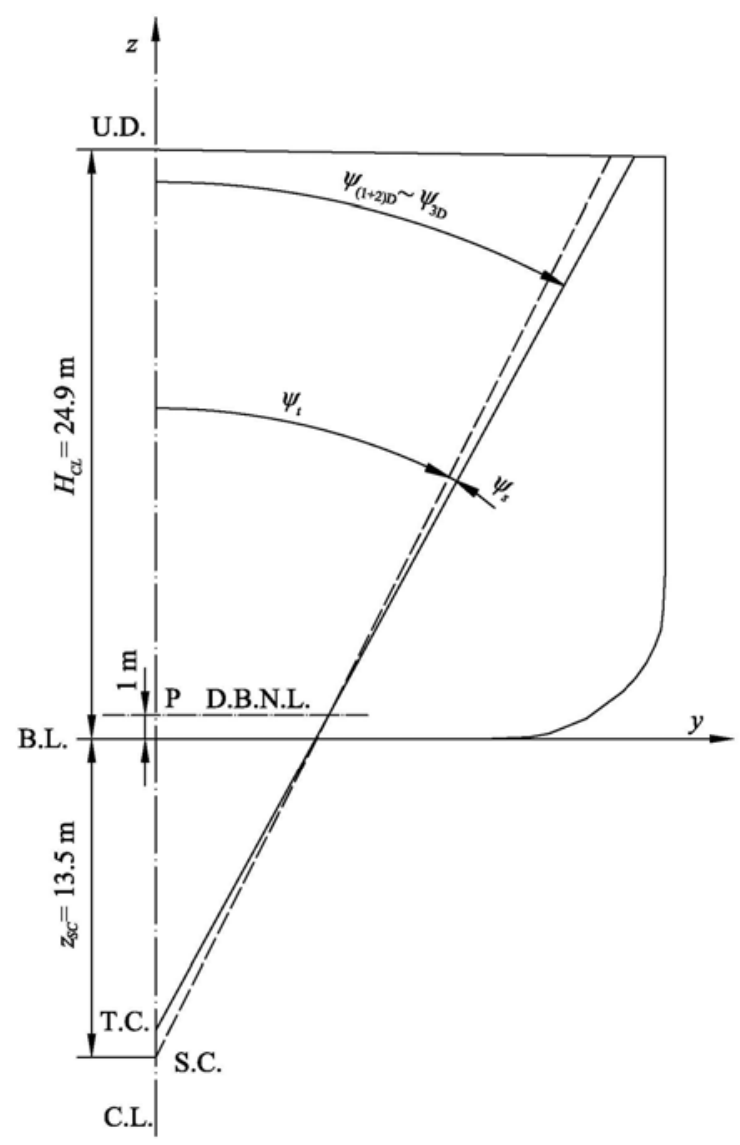

Figure 17. Twist angle at the pontoon end.
Pure twist angle $\psi_{t}$ is realized around the shear centre, S.C., and is somewhat smaller then the twist angle determined by 3D FEM model. If the shear twist angle $\psi_{s}$ is added to $\psi_{s}$ around the double bottom centroid, value of the total twist angle approaches that of $3 \mathrm{D}$ analysis. As a result, the twist centre is determined, T.C.

\section{CONCLUDING REMARKS}

Ultra large container ships are quite flexible so they stretch the bounds of present classification rules for reliable structural design. Therefore, hydroelastic analysis has to be performed (Senjanović et al. 2008a, 2009a)

The illustrative numerical example of the 7800 TEU container ship shows that the developed hydroelasticity theory, utilizing the improved 1D FEM structural model and 3D hydrodynamic model, is an efficient tool for application in ship hydroelastic analyses. The obtained results point out that the transfer functions of hull sectional forces in case of resonant vibration (springing) are much higher than in resonant ship motion. Very good agreement between ship response determined by hydroelastic analysis and rigid body analysis in vicinity of zero frequency is obtained due to use of the consistent restoring stiffness. The both solutions converge to zero, as frequency approaches zero value.

The used advanced beam model of ship hull, based on advanced thin-walled girder theory with included shear influence on torsion and contribution of transverse bulkheads to stiffness, is a reasonable choice for determining wave load effects. However, stress concentration in hatch corners calculated directly by the beam model is underestimated. This problem can be overcome by applying substructure approach, i.e. 3D FEM model of substructure with imposed boundary conditions from beam response. In any case, 3D FEM model of complete ship is preferable from the viewpoint of determining stress concentration.

In order to complete hydroelastic analysis of container ships and confirm its importance for ship safety, it is necessary to proceed further to ship motion calculation in irregular waves for different sea states, based on the known transfer functions. This includes determination of global wave loads, i.e. bending and torsional moments and their conversion into stresses, stress concentration in critical areas of ship structures, especially in hatch corners due to restrained warping, and fatigue of structural details.

At the end of a complete investigation, which also has to include model tests and full-scale measurements, it will be possible to decide on the extent of 
the revision of Classification Rules for the design and construction of ultra large container ships.

\section{REFERENCES}

Bathe, KJ. 1996. Finite Element Procedures. Prentice Hall.

Bishop, RED. \& Price WG. 1979. Hydroelasticity of Ships. Cambridge University Press.

Haslum, K., Tonnessen, A. 1972. An analysis of torsion in ship hull. European Shipbuilding (5/6): 67-89.

Huang, LL., Riggs, HR.. 2000. The hydrostatic stiffness of flexible floating structure for linear hydroelasticity. Marine Structures 13: 91-106.

Kawai, T. 1973. The application of finite element method to ship structures. Computers and Structures (2): 1175-1194.

Malenica, Š. 2003. Some aspects of hydrostatic calculations in linear seakeeping. Proc. $14^{\text {th }}$ NAV Conf., Palermo.

Malenica, Š., Molin, B., Remy, F., Senjanović, I. 2003. Hydroelastic response of a barge to impulsive and nonimpulsive wave load. Proc. Hydroelasticity in Marine Technology, Oxford, 287-314.

Malenica, Š., Senjanović, I., Tomašević, S., Stumpf, E. 2007. Some aspects of hydroelastic issues in the design of ultra large container ships. Proc. IWWWFB, Plitvice Lakes.

Newman, JN. 1994. Wave effects on deformable bodies. Applied Ocean Research 16: 47-59.

Pavazza, R. 2005. Torsion of thin-walled beams of open crosssections with influence of shear. International Journal of Mechanical Sciences 47: 1099-1122.

Pedersen, PT. 1985. Torsional response of container ships. Journal of Ship Research 31: 194-205.

Price, WG, Wu, Y. 1985. Hydroelasticity of Marine Structures. In: Theoretical and Applied Mechanics, FI. Niordson \& N. Olhoff, eds. Elsevier Science Publishers B.V.: 311-337.

Remy, F., Molin, B., Ledoux, A. 2006. Experimental and numerical study of the wave response of flexible barge. Proc. Hydroelasticity in Marine Technology, Wuxi, 255-264.

Salvesen, N., Tuck, EO., Faltinsen, OM. 1970. Ship motion and sea loads. Cambridge University Press.

Senjanović, I. 1998. Finite Element Method in Ship Structures. University of Zagreb, Zagreb, (in Croatian).

Senjanović, I. Fan, Y. 1989. A higher-order flexural beam theory. Computers \& Structures 32(5): 973-986.

Senjanović, I. Fan, Y. 1992. A higher-order theory of thinwalled girders with application to ship structures. Computers \& Structures 43(1): 31-52.

Senjanović, I. Fan, Y. 1997. A higher-order torsional beam theory. Engineering Modelling 32(1-4): 25-40.

Senjanović, I. Grubišić, R. 1991. Coupled horizontal and torsional vibration of a ship hull with large hatch openings. Computers \& Structures 41(2): 213-226.

Senjanović, I., Malenica, Š, Tomašević, S, Rudan, S. 2007. Methodology of ship hydroelastic investigation. Brodogradnja 58(2): 133-145.

Senjanović, I., Tomašević, S., Tomić, M., Rudan, S., Vladimir, N. 2008a. Hydroelasticity of Very Large Container Ships. Proc. Design and Operation Of Container Ships, RINA, London, 51-70.

Senjanović, I., Tomašević, S, Rudan, S, Senjanović, T. 2008 b. Role of transverse bulkheads in hull stiffness of large container ships. Engineering Structures 30: 2492-2509.

Senjanović, I., Tomašević, S., Vladimir, N., Tomić, M., Malenica, Š. 2009a. Ship hydroelastic analysis with sophisticated beam model and consistent restoring stiffness. Proc. Hydroelasticity in Marine Technology, University of Southampton, Southampton, 69-80.

Senjanović, I., Tomašević, S., Vladimir, N., Malenica, Š. 2009b. Numerical procedure for ship hydroelastic analysis.
Proc. Intl. Conf. Computational Methods in Marine Eng., CIMNE, Barcelona, 259-264.

Senjanović, I., Tomašević, S., Vladimir, N. 2009c. An advanced theory of thin-walled girders with application to ship vibrations. Marine Structures 22(3): 387-437.

Senjanović, I., Malenica, Š., Tomašević, S. 2009d. Hydroelasticity of large container ships. Marine Structures 22(2): $287-314$

Tomašević, S. 2007. Hydroelastic model of dynamic response of Container ships in waves. Doctoral Thesis, University of Zagreb, Zagreb, (in Croatian).

Szilard, R. 2004. Theories and Applications of Plate analysis. John Wiley \& Sons, New York.

Vlasov, VZ. 1961. Thin-Walled Elastic Beams. Israel Program for Scientific Translation, Jerusalem.

Wu, JS., Ho, CS. 1987. Analysis of wave induced horizontal and torsion coupled vibrations of ship hull. Journal of Ship Research 31(4): 235-252. 